Article

\title{
Effects of Cerium on Weld Solidification Crack Sensitivity of 441 Ferritic Stainless Steel
}

\author{
Shuangchun Zhu ${ }^{1,2}$ and Biao Yan ${ }^{1, *}$ \\ 1 School of Materials Science and Engineering, Tongji University, Shanghai 201804, China; \\ zhushuangchun@baosteel.com \\ 2 Central Research Institute, Baoshan Iron \& Steel Co., Ltd., Shanghai 201900, China \\ * Correspondence: yan_biao@tongji.edu.cn; Tel.: +86-21-6958-2007
}

Received: 26 February 2019; Accepted: 13 March 2019; Published: 22 March 2019

\begin{abstract}
The addition of rare earth element Ce in ferritic stainless steel can improve the high temperature performance to meet the service requirements of automobile exhaust systems at high temperatures. Automobile exhaust systems are generally applied as welded pipes, so it is necessary to study the effect of Ce on the weldability of ferritic stainless steel. In this study, the Trans-varestraint test method was used to test the solidification crack sensitivities of 441 and 441Ce ferritic stainless steel. The 441Ce steel, which has added Ce, showed poor resistance to weld solidification cracking. Using Thermo-Calc software, Ce was observed to expand the solidification temperature range of 441 ferritic stainless steel, increase the time for solid-liquid coexistence during solidification, and increase the sensitivity of solidification cracking. Further, from scanning electron microscopy and energy dispersive spectrometer analysis, the addition of $\mathrm{Ce}$ was found to reduce high temperature precipitation $(\mathrm{Ti}, \mathrm{Nb})(\mathrm{C}, \mathrm{N})$, reduce or even eliminate the "pinning" effect during solidification, and increase solidification crack sensitivity of 441 ferritic stainless steel.
\end{abstract}

Keywords: ferritic stainless steel; cerium; solidification crack; Trans-varestraint test

\section{Introduction}

As an important type of stainless steel, ferritic stainless steel has been a popular focus of research and application in recent years, not only because of its lack of nickel content but also because it is economical. Its cost is not affected by fluctuations in international nickel prices, and compared with austenitic stainless steel, ferritic stainless steel too has good thermal conductivity, low thermal expansion coefficient, good high temperature oxidation resistance, and good high temperature thermal fatigue resistance; thus, it has a wide range of applications in automotive exhaust systems [1-4]. However, with the constantly increasing requirements of automobile exhaust emission standards, automobile engine technology is continuously improving, and the exhaust gas temperature is continuously increasing. Better high temperature performance requirements are therefore imposed on the high temperature end material of the exhaust system [5-7].

Rare earth elements have a unique electronic layer structure and active chemical properties. In stainless steel, they can clean the steel, metamorphose inclusions, control solidification structure, and refine the grain [8-12], so they have received much attention from scholars these days. Some scholars have shown that the addition of rare earth elements in ferritic stainless steel can improve its corrosion resistance, mechanical properties, high temperature performance, and other service properties [13-16]. In order to study and improve the high temperature oxidation resistance, previously reported studies $[17,18]$ show that adding Ce can increase densification of the oxidation film of ferritic stainless steel and improve its high temperature oxidation resistance. However, research data on the influence of rare earth elements on weld solidification crack sensitivity is still lacking. Automobile 
exhaust systems are generally applied as welded pipes, so the alloying effect on the weldability of ferritic stainless steel needs to be investigated. Only with excellent weldability can the alloyed stainless steel be utilized commercially. In this study, the 441 type ferritic stainless steel is the research object. The effect of Ce on the weld solidification crack sensitivity of 441 ferritic stainless steel and its mechanism were studied using the Trans-varestraint test, and the theoretical support for solidification crack control of Ce-containing ferritic stainless steel is provided.

\section{Materials and Methods}

The test materials used were two types of hot-rolled ferritic stainless steel. The chemical compositions of the test materials are shown in Table 1. The Trans-varestraint test method was used to evaluate the solidification crack sensitivities of these materials. The test equipment utilized the MTV2500 testing system produced by D. L. Wright Inc. Samples of dimensions $120 \mathrm{~mm} \times$ $30 \mathrm{~mm} \times 6 \mathrm{~mm}$ without the weld groove were machined for the Trans-varestraint tests. The weld was completed by arc remelting, and the remelting position and experimental principle are shown schematically in Figure 1 [19]. The principle of this method is to apply different strain values to study the crack generation. An autogenous gas tungsten arc welding method was used to melt the weld bead. The welding current and arc voltage were $150 \mathrm{~A}$ and $17 \mathrm{~V}$, respectively. The welding speed was $100 \mathrm{~mm} / \mathrm{min}$. The welding shielding gas used was $99.999 \%$ argon gas, and the gas flow rate was $121 / \mathrm{min}$. Nine series of strains (i.e. $0 \%, 0.25 \%, 0.50 \%, 1 \%, 2 \%, 3 \%, 4 \%, 5 \%$ and $6 \%$ ) were used in the tests. The Trans-varestraint tests were performed in increasing order of strain from small to large values.

The surface cracks of the welds of the specimens that have completed the Trans-varestraint test are observed by scanning electron microscopy (SEM, ZEISS EVO MA 25, ZEISS Group, Cambridge, UK) to note the occurrence of cracks and to measure the lengths of these cracks. Metallographic specimens of the weld cross section were cut from the tested specimens under $0 \%$ strain. The specimens were machined, polished, corroded (corrosive solution, $\mathrm{FeCl}_{3}: \mathrm{HCl}: \mathrm{H}_{2} \mathrm{O}=5 \mathrm{~g}: 50 \mathrm{~mL}: 100 \mathrm{~mL}$ ), cleaned with anhydrous ethanol, and dried. The microstructures of the specimens were observed by SEM (FEI QUANTA 600F, FEI Company, Eindhoven, Netherlands) and equipped with an energy dispersive spectrometer (EDS, OXFORD INCAx-act, Oxford Instruments, Oxfordshire, UK). The Scheil solidification simulation module of the thermodynamic calculation software Thermo-Calc was used along with the TCFE9 database to simulate the stainless steel welding solidification process.

Table 1. Chemical compositions of test materials (wt $\%$ ).

\begin{tabular}{ccccccccccc}
\hline Steel & $\mathbf{C}$ & $\mathbf{S i}$ & $\mathbf{M n}$ & $\mathbf{P}$ & $\mathbf{S}$ & $\mathbf{C r}$ & $\mathbf{N b}$ & $\mathbf{N}$ & $\mathbf{T i}$ & $\mathbf{C e}$ \\
\hline 441 & 0.005 & 0.380 & 0.340 & 0.008 & 0.002 & 18.630 & 0.430 & 0.008 & 0.140 & - \\
$441 \mathrm{Ce}$ & 0.008 & 0.360 & 0.310 & 0.008 & 0.001 & 18.440 & 0.460 & 0.008 & 0.190 & 0.024 \\
\hline
\end{tabular}

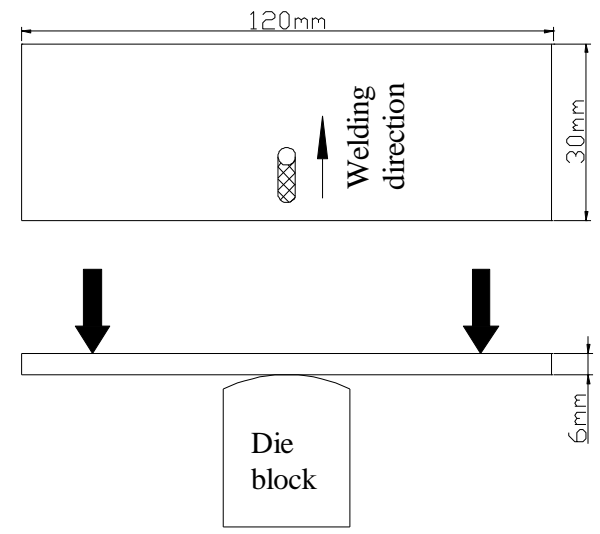

Figure 1. Trans-varestraint test. 


\section{Results and Discussion}

\subsection{Threshold Strain and Maximum Crack Distance}

There are many quantitative indicators for evaluating the thermal crack sensitivities of materials. In this study, the threshold strain and maximum crack distance (MCD) are used as evaluation indexes of weld solidification cracks. Threshold strain refers to the strain at crack initiation during a Trans-varestraint test for a series of small to large strains. Saturation strain refers to the strain that exceeds the threshold value where the maximum crack length no longer shows a significant change; the MCD refers to the maximum crack length (MCL) measured for each value of the test strain above the saturation strain. Figure 2 shows the MCLs of the test materials for the transverse variable restraint welding solidification crack test under various strains. It can be seen from the graph that the threshold strain of the 441 ferritic stainless steel is between $0.5 \%$ and $1 \%$, whereas the threshold strain of the $441 \mathrm{Ce}$ ferritic stainless steel is between $0 \%$ and $0.25 \%$. The MCD values for 441 and $441 C$ ferritic stainless steels are $239.5 \pm 0.1 \mu \mathrm{m}$ and $290.0 \pm 0.1 \mu \mathrm{m}$, respectively. Thus, it can be concluded that the addition of Ce increases the weld solidification crack sensitivity of 441 ferritic stainless steel.

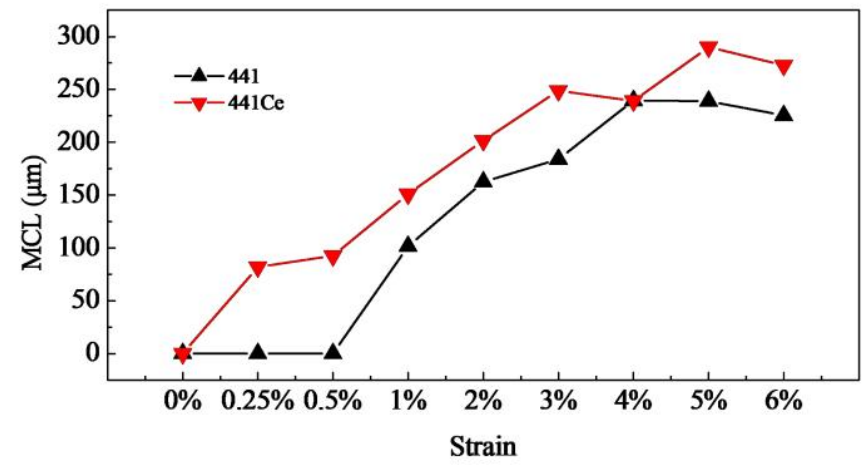

Figure 2. MCLs of the test materials under various strains.

\subsection{Thermodynamic Calculation of Solidification Process}

Table 2 shows the solidification temperature range obtained from simulation calculation. It can be seen that the solidification temperature range of the 441Ce material with the rare earth element Ce reached $199{ }^{\circ} \mathrm{C}$, which is approximately $14^{\circ} \mathrm{C}$ higher than that of the 441 material, indicating that Ce expands the solidification temperature range. Thus, Ce addition increases the area and time of solid-liquid coexistence during solidification, greatly increases the risk of solidification cracking, and reduces the ability of stainless steel to resist solidification cracking.

Table 2. The solidification temperature range obtained by simulation calculation.

\begin{tabular}{cccc}
\hline Steel & $\begin{array}{c}\text { Solidification Start } \\
\text { Temperature } /{ }^{\circ} \mathbf{C}\end{array}$ & $\begin{array}{c}\text { Solidification End } \\
\text { Temperature } /{ }^{\circ} \mathbf{C}\end{array}$ & $\begin{array}{c}\text { Solidification } \\
\text { Temperature Range } /{ }^{\circ} \mathbf{C}\end{array}$ \\
\hline 441 & 1504 & 1319 & 185 \\
$441 \mathrm{Ce}$ & 1502 & 1303 & 199 \\
\hline
\end{tabular}

\subsection{Solidification Crack Distribution and Morphology}

Figure 3 depicts the crack distribution and morphology of the test specimen under Trans-varestraint test for the 5\% strain condition. The direction of the columnar crystal of the weld is mostly perpendicular to the fusion line during solidification crystallization. This is because the liquid metal solidifies and crystallizes along the direction of the temperature gradient. When the columnar crystal grows, there is a liquid phase film between the front columnar crystals of the solidification interface. At this time, a transverse strain is applied to the welding metal, and the liquid phase film 
that has not solidified at the grain boundary is insufficient to fill the gap generated by the strain, thus forming cracks at the grain boundary. As can be seen from Figure 3, the cracks are primarily situated at the grain boundary position, verifying that the solidification cracks occur between the columnar crystals.

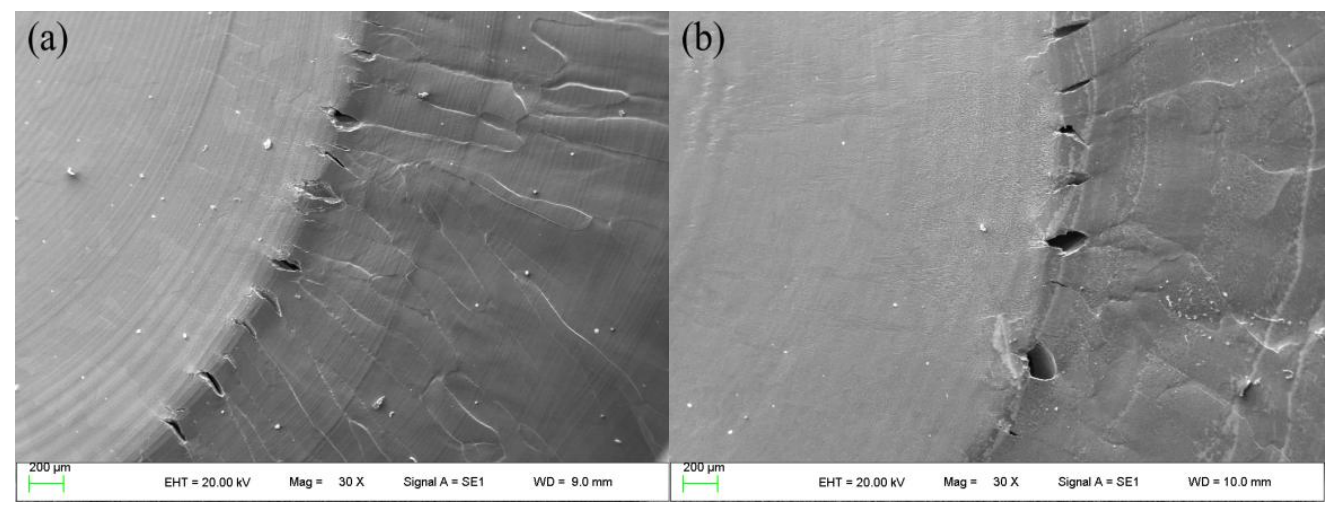

Figure 3. Crack distributions and morphologies under 5\% strain for (a) 441 and (b) $441 \mathrm{Ce}$ type materials.

Figure 4 shows the typical shape of a crack formed in the Trans-varestraint test, which applies instantaneous strain to the specimen. Under the application of a sudden strain, owing to the temperature difference of the instantaneous cracking zone, the solidification crack morphology produced by the Trans-varestraint test has the characteristics of both high and low temperature zones [20]. The high temperature zone is close to the crystal front and shows the characteristics of liquid phase fracture; the liquid film traces at the time of fracture are visible between the crystals. Peng et al. [21] believe that the crystallization process of the columnar crystal at the moment of cracking in the high temperature region is complete or nearly complete, and the connection, contact, and void formation of adjacent columnar crystals are also complete; this means that at this moment, the adjacent columnar crystals have only the connections of the residual low-melting of the liquid phase film and the liquid bridge forms. The low temperature zone refers to the zone of solidification cracking that is away from the crystallization front. In this zone, it is observed that the columnar crystal plane with complete crystal morphology has annular or striped ridges, and the arrangement direction of each annular ridge and the main direction of the striped ridges are roughly parallel to the direction of the columnar crystals, similar to a waterfall; the low temperature zone is close to final solidification (i.e., in a liquid-solid zone with poor fluidity), which is pulled apart under a large tensile strain and forms the characteristic shapes of the annular and striped ridges.

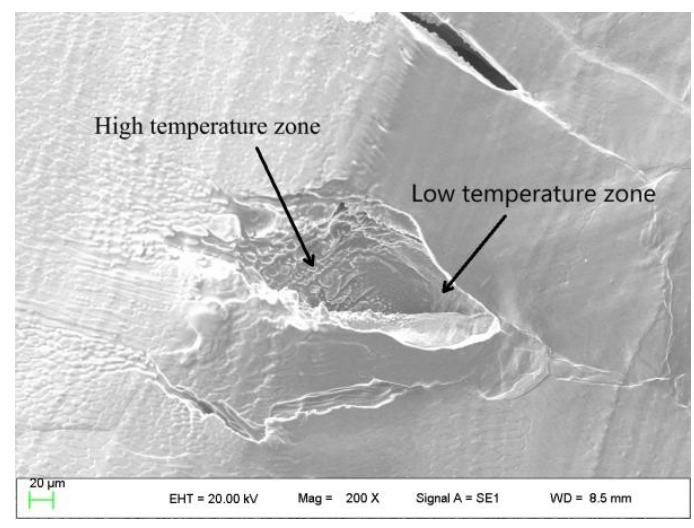

Figure 4. Typical morphology of a crack. Test material: 441 steel, test strain: 5\%. 


\subsection{Precipitation}

Figure 5 shows the metallographic structure of the weld cross-section after application of the Trans-varestraint test for the $0 \%$ strain condition, as observed under scanning electron microscopy (SEM). It can be seen from the figure that a large number of precipitates appear in the intragranular and grain boundaries of the 441 material. The precipitates of 441Ce are relatively small. This indicates that the addition of the alloying element Ce reduces the generation of the precipitated phase and has a purifying effect on the grain boundary as well as the crystal inside, thus greatly influencing the hot crack sensitivity and strength of the material.

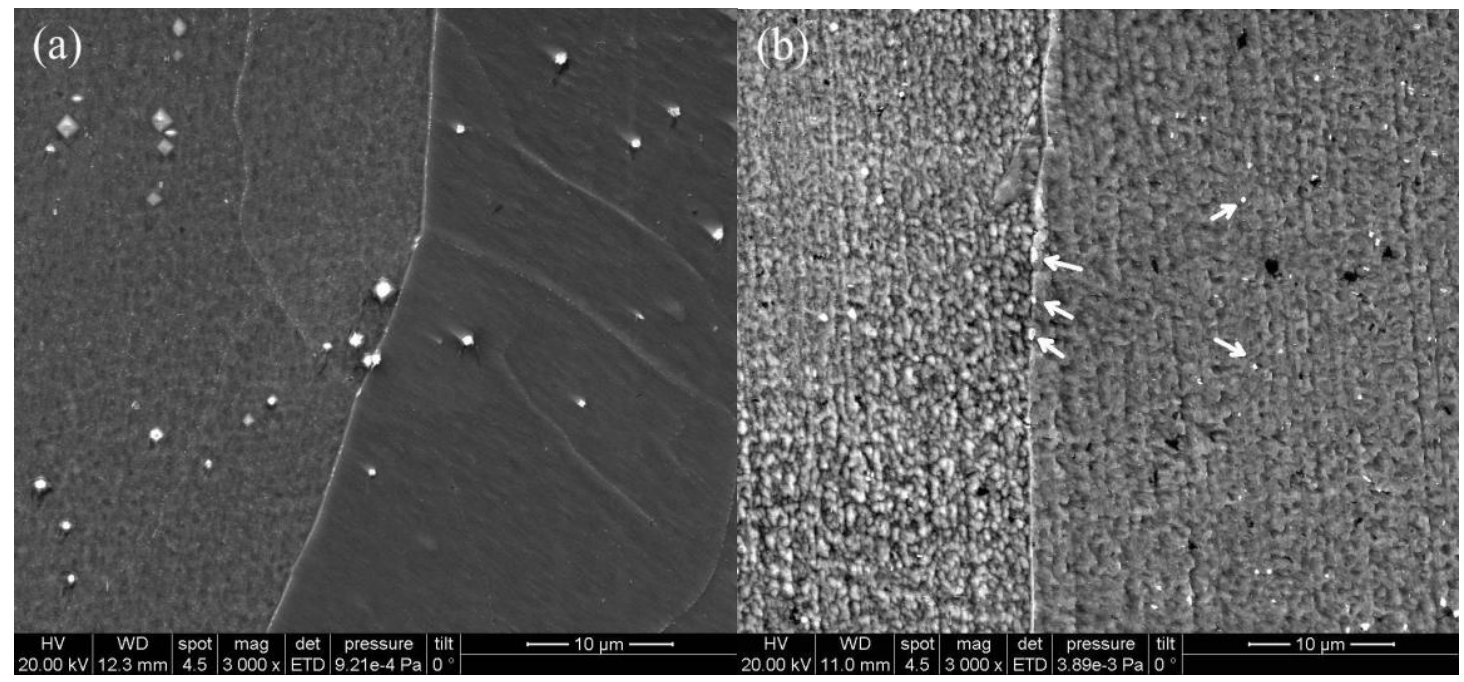

Figure 5. Metallographic structures of the weld cross-sections of (a) 441 and (b) 441Ce type steel.

The grain boundary of the metallographic structure of each weld cross-section was further magnified under SEM, and energy dispersive spectrometer (EDS) analysis was performed on the precipitation on the grain boundary. The results are shown in Figure 6. The precipitation of the 441 weld grain boundary is granular, and the size is approximately $1 \mu \mathrm{m}$. The EDS result shows that it is a composite precipitation rich in $\mathrm{Fe}, \mathrm{Cr}$, $\mathrm{Ti}$, and $\mathrm{Nb}$. The precipitation of the 441Ce weld grain boundary is relatively small, and the spectrum of the precipitation is similar to that of the 441 weld grain boundary. The thermodynamic calculation results in Table Table 2 indicate that Ce expands the solidification temperature range, increases the degree of undercooling during the solidification process, promotes heterogeneous nucleation and growth of the liquid metal during solidification, increases the grain boundary, and refines the grain, so that the precipitated phase is dispersed. In addition, rare earth elements can reduce the activity of $C$, increase the solubility of $C$, and reduce the precipitation of carbides of $\mathrm{Ti}$ and $\mathrm{Nb}$ during solidification [22]. Ce is easily segregated near the grain boundary because in the cooling process following the solidification of the weld, the radius of the Ce atom is large, which tends to segregate Ce near the grain boundary, thus causing lattice expansion near the grain boundary and increasing its energy. It is easy to nucleate the carbide [23] so that the precipitation of the grain boundary is fine and exhibits a dispersed distribution. 

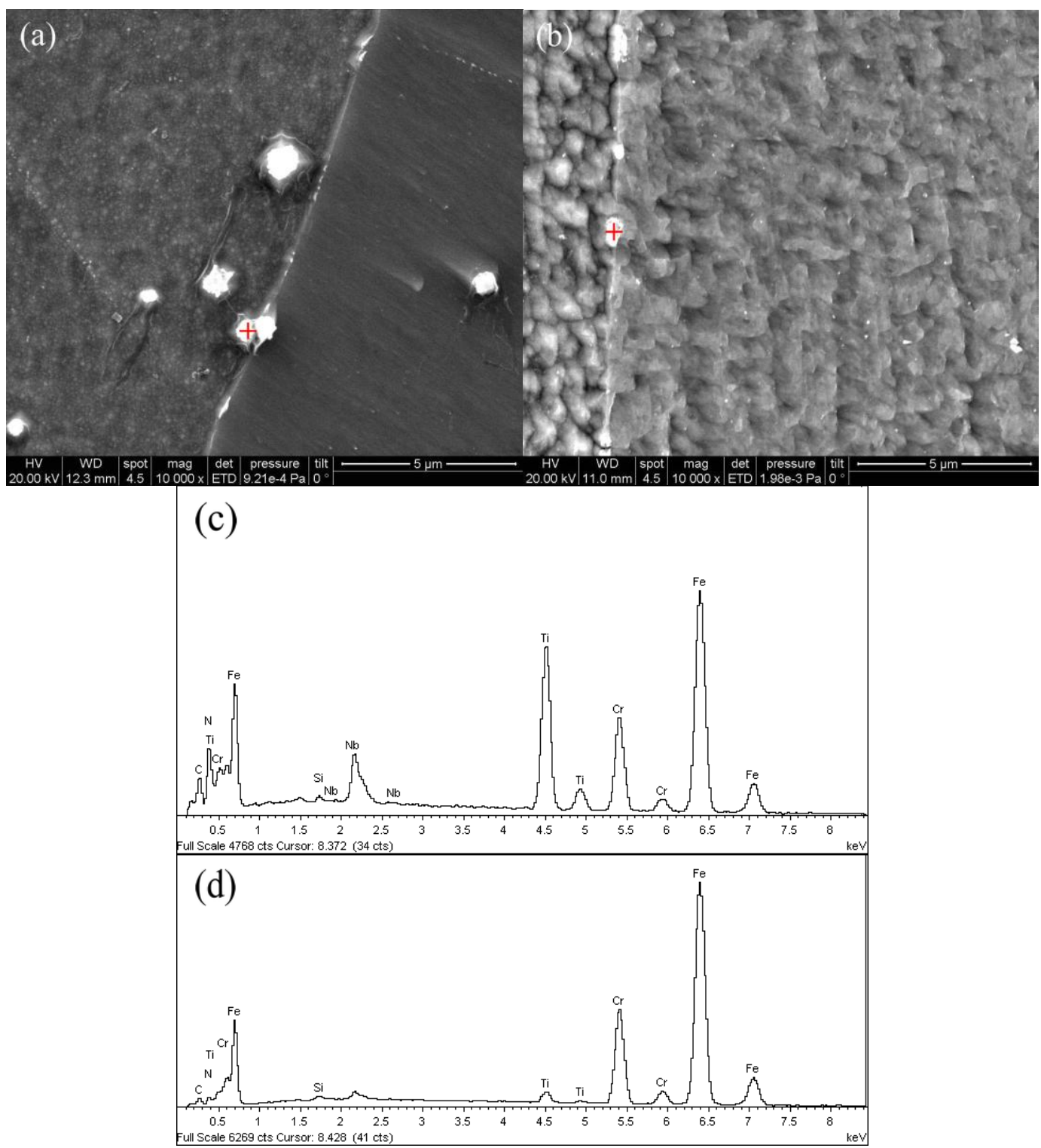

Figure 6. SEM images and EDS analyses of precipitations on the grain boundaries of $(\mathbf{a}, \mathbf{c}) 441$ and $(\mathbf{b}, \mathbf{d})$ 441Ce type materials, respectively.

Figure 7 depicts the phase-temperature equilibrium diagrams of 441 and 441Ce steel using Thermo-Calc software. When 441 ferritic stainless steel solidifies, it produces high melting point precipitates $(\mathrm{Ti}, \mathrm{Nb})(\mathrm{C}, \mathrm{N})$. Some of these precipitations occur on the solidification grain boundary, destroying the liquid film that has not yet solidified at the boundary, improving the bonding strength of the boundary, and forming a "pinning" effect, as shown in Figure 8. This effect reduces the sensitivity of the weld solidification crack. Compared to the 441 stainless steel without added Ce, 441Ce increases the solidification temperature range, prolongs the total time of the weld in the solid-liquid mixing stage during the welding cooling process, and greatly increases the risk of solidification cracking. In addition, the Ce atoms are segregated on the grain boundary during solidification [23], which easily forms a low-melting liquid film. Because Ce promotes a solid solution of C [23], it is not conducive to precipitation of carbides of $\mathrm{Ti}$ and $\mathrm{Nb}$, thus reducing such precipitations. Further, it reduces the pinning effect of precipitation, so the addition of Ce greatly improves the weld solidification crack sensitivity of 441 ferritic stainless steel. 

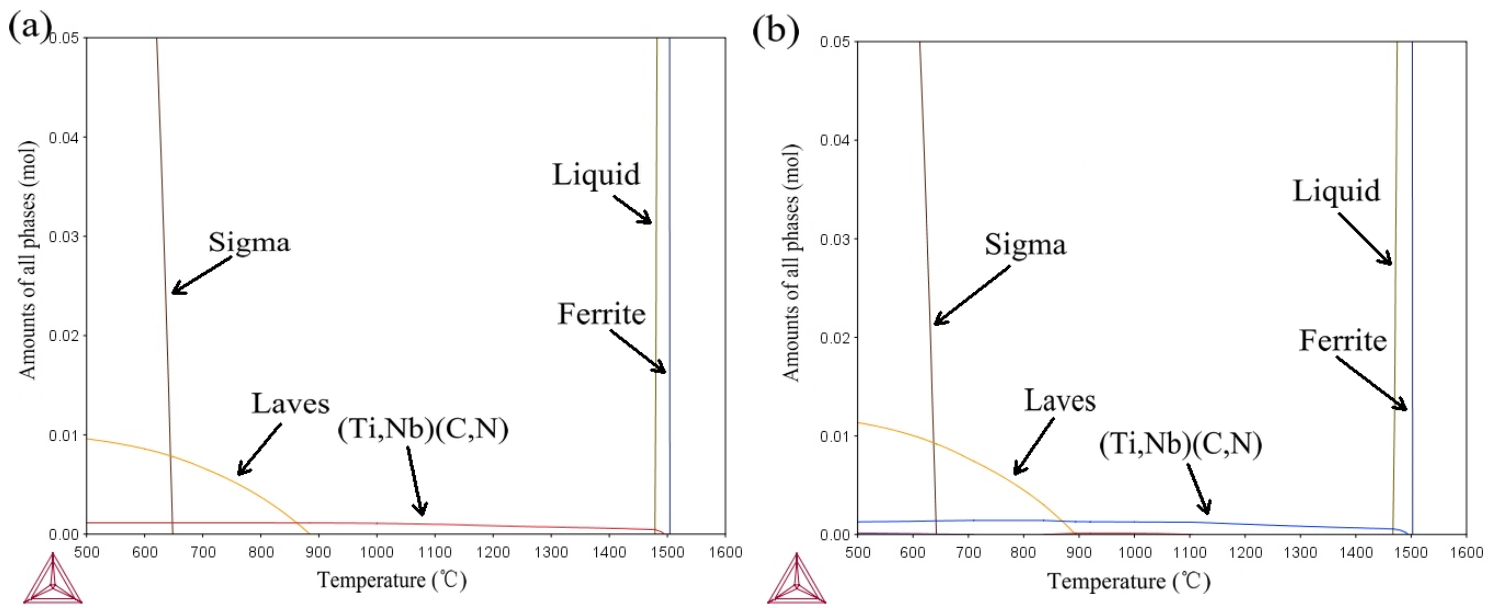

Figure 7. Phase-temperature equilibrium diagrams for (a) 441 and (b) 441Ce type ferritic stainless steel materials.

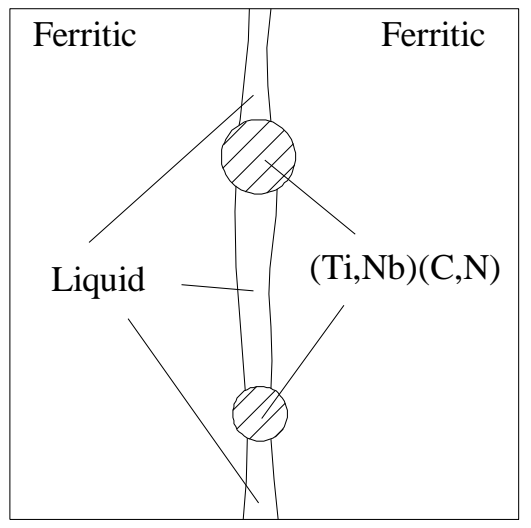

Figure 8. Pinning effect of precipitation in the solidification grain boundary.

\section{Conclusions}

The sensitivity of the solidification crack of 441 ferritic stainless steel can be improved by adding the rare earth element $\mathrm{Ce}$; the observations and conclusions of such an addition are as follows:

(1) Ce widens the solidification temperature range of 441 ferritic stainless steel, so in the actual welding process, it increases the duration of the weld metal in the solid-liquid mixing stage, thus improving the solidification crack sensitivity of stainless steel.

(2) The high temperature precipitates produced during solidification of 441 ferritic stainless steel weld metal, especially at the solid-liquid interface, can pin the interface, improve the bonding strength of the interface, and prevent the solidification cracks. After adding Ce to 441 ferritic stainless steel, the precipitates produced in the weld can be reduced and the weld structure can be purified. It is precisely because of this purifying effect that the pinning due to high temperature precipitates in the solidification process of the weld metal is weakened and solidification crack sensitivity is improved.

(3) In a future work, the influence of $\mathrm{Ce}$ on solidification temperature range and the precipitates will be studied in depth, and the improvement of the anti-solidification crack properties of Ce-containing ferritic stainless steel will be explored.

Author Contributions: Conceptualization: S.Z. and B.Y.; investigation: S.Z.; original draft preparation: S.Z.; review and editing: S.Z. and B.Y.

Funding: This research received no external funding.

Acknowledgments: This work was supported by the Baoshan Iron \& Steel Co., Ltd.

Conflicts of Interest: The authors declare no conflict of interest. 


\section{References}

1. Bi, H.Y.; Wang, Z.Y.; Li, X.; Wang, B.S. Stainless steel for automotive exhaust system and pipes welding. World Iron Steel 2011, 5, 1-9. [CrossRef]

2. Kim, J.K.; Kim, Y.H.; Uhm, S.H.; Lee, J.S.; Kim, K.Y. Intergranular corrosion of Ti-stabilized 11 wt $\%$ Cr ferritic stainless steel for automotive exhaust systems. Corros. Sci. 2009, 51, 2716-2723. [CrossRef]

3. Ali-Löytty, H.; Jussila, P.; Valden, M. Optimization of the electrical properties of Ti-Nb stabilized ferritic stainless steel SOFC interconnect alloy upon high-temperature oxidation: The role of excess $\mathrm{Nb}$ on the interfacial oxidation at the oxide-metal interface. Int. J. Hydrogen Energy 2013, 38, 1039-1051. [CrossRef]

4. Inoue, Y.; Kikuchi, M. Present and future trends of stainless steel for automotive exhaust system. Nippon Steel Tech. Rep. 2003, 88, 62-69.

5. Sato, E.; Tanoue, T. Present and future trends of materials for automotive exhaust system. Nippon Steel Tech. Rep. 1995, 64, 13-19.

6. Miyazaki, A.; Hirasawa, J.; Satoh, S. Advanced stainless steels for stricter regulations of automotive exhaust gas. Kawasaki Steel Tech. Rep. 2000, 43, 21-28.

7. Li, X.; Bi, H.Y.; Zhang, Z.X. Development of ferritic stainless steels at Baosteel for the hot end of the exhaust system. Baosteel Technol. 2013, 5, 15-21. [CrossRef]

8. Keming, F.; Ruiming, N. Research on determination of the rare earth content in metal phases of steel. Metall. Trans. A 1986, 17, 315-323. [CrossRef]

9. $\mathrm{Du}, \mathrm{T}$. The effect and mechanism of rare earth elements in metals. Chin. J. Nonferrous Met. 1996, 6, 12-18. [CrossRef]

10. Chen, Z.P.; Xu, Y.T.; Gu, L.M. Effect of Rare Earth on the Inclusions of Ultra Clean Ferritic Stainless Steel. In Proceedings of the 2012 National Conference on Metallurgical Physical Chemistry, Kunming, China, 15-17 August 2012; pp. 652-656.

11. Wang, L.M. Application prospects and behavior of RE in new generation high strength steels with superior toughness. J. Chin. Rare Earth Soc. 2004, 22, 48-54.

12. Zhang, S.H.; Yu, Y.C.; Li, H.; Ren, X.; Wang, S.B. Effect of cerium on solidification structure of SUS434 ferritic stainless steel. Foundry Technol. 2016, 37, 2641-2644. [CrossRef]

13. Dong, F.; Zhao, X.H.; Yang, L. Effect of Ce on intergranular corrosion of 00Cr12 ferrite stainless steel. Chin. Rare Earths 2014, 35, 86-91. [CrossRef]

14. Zheng, F.; Cheng, T.Y.; Zhang, Q.Y. Application and development of cerium in stainless steel. Nonferrous Met. 2011, 63, 78-80. [CrossRef]

15. Sun, S.Y.; Yuan, S.Q.; Zhou, G.S.; Chai, D.L. Influence of rare earth element on the mechanical properties and microstructure of ferritic stainless steel. Trans. Mater. Heat Treat. 2007, 28, 22-24. [CrossRef]

16. Zhu, J.X.; Chen, D.X.; Qi, G.P.; Ge, Q.; Chen, X.; Cai, Z.; Wang, L.M. Modifications on Resistance to High-Temperature-Oxidation of AISI430 Ferrite Stainless Steel by Addition of Rare Earth Elements. In Proceedings of the 2006 National Conference on Metallurgical Physical Chemistry, Jinan, China, 17-20 October 2006; pp. 490-496.

17. Wei, L.L.; Zheng, J.H.; Chen, L.Q.; Misra, R.D.K. High temperature oxidation behavior of ferritic stainless steel containing W and Ce. Corros. Sci. 2018, 142, 79-92. [CrossRef]

18. Wei, L.L.; Chen, L.Q.; Ma, M.Y.; Liu, H.L.; Misra, R.D.K. Oxidation behavior of ferritic stainless steels in simulated automotive exhaust gas containing 5 vol.\% water vapor. Mater. Chem. Phys. 2018, 205, 508-517. [CrossRef]

19. Lippold, J.C. Welding Metallurgy and Weldability; John Wiley \& Sons, Inc.: Hoboken, NJ, USA, 2015; pp. 345-346.

20. Lu, W.X.; Meng, Q.S.; Yang, S.J. The crystal crack form and the fracture character of austenitic weld under the Trans-varestraint hot crack test. J. Taiyuan Univ. Technol. 1986, 1, 21-27. [CrossRef]

21. Peng, R.H.; Li, M.Z.; Sun, L.M. Investigation on the dendrites in weld metals of austenitic heat-resistant cast steels and on the fracture appearance of solidification cracks. J. Iron Steel Res. 1985, 5, 307-311. [CrossRef] 
22. Zhao, L.P.; Zhang, H.M.; Sun, X.S.; Cui, C.Y. Effect of adding methods and addition amount of Ce on microstructure of 2Cr13 stainless steel. Trans. Mater. Heat Treat. 2012, 33, 91-94. [CrossRef]

23. Li, Y.B.; Wang, F.M.; Li, C.R. Effect of cerium on grain and carbide in low chromium ferritic stainless steels. J. Chin. Rare Earth Soc. 2009, 27, 123-127.

(c)

(C) 2019 by the authors. Licensee MDPI, Basel, Switzerland. This article is an open access article distributed under the terms and conditions of the Creative Commons Attribution (CC BY) license (http:/ / creativecommons.org/licenses/by/4.0/). 